\title{
Comparative effectiveness of a standard behavioral and physical activity enhanced behavioral weight loss intervention in Black women
}

\author{
Loneke T. Blackman Carr ${ }^{\mathrm{a}, \mathrm{b}}$, Carmen D. Samuel-Hodge ${ }^{\mathrm{b}}$, Dianne S. Ward ${ }^{\mathrm{b}}$, \\ Kelly R. Evenson ${ }^{b}$, Shrikant I. Bangdiwalac, and Deborah F. Tate ${ }^{d}$

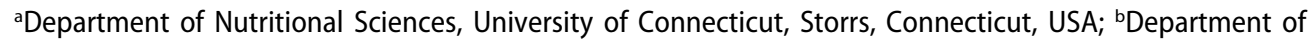 \\ Nutrition, University of North Carolina at Chapel Hill, Chapel Hill, North Carolina, USA; 'Department of Health \\ Research Methods, Evidence and Impact, McMaster University, Hamilton, Ontario, Canada; ${ }^{\mathrm{d} D e p a r t m e n t}$ of \\ Health Behavior, Department of Nutrition, University of North Carolina at Chapel Hill, Chapel Hill, North \\ Carolina, USA
}

\begin{abstract}
Black women typically lose small amounts of weight in behavioral weight loss interventions, partially due to low engagement in physical activity. Culturally relevant enhancement of the physical activity component may improve weight loss. This study compared the effectiveness of a culturally-relevant, physical activity-enhanced behavioral weight loss intervention to a standard behavioral weight loss intervention in Black women $(n=85)$ over 6 months. The study was conducted in two cohorts from March 2016 to February 2017 at the University of North Carolina at Chapel Hill. Participants had an average age of $48.30 \pm 11.02$ years with an average body mass index of $36.46 \pm 4.50 \mathrm{~kg} / \mathrm{m}^{2}$. Standard and enhanced groups' weight change $(-2.83 \mathrm{~kg}$ and $-2.08 \mathrm{~kg}$, respectively) and change in physical activity (43.93 $\mathrm{min} /$ week and $15.29 \mathrm{~min} /$ week, respectively) did not differ between groups. Significantly more standard group participants lost $5 \%$ of baseline weight compared to enhanced group participants. This study produced typical weight loss results in Black women. Behavioral weight loss treatment remains moderately effective for Black women. Strategies to increase attendance and self-monitoring, and the inclusion of cultural contexts to weight-related behaviors are needed to improve outcomes.
\end{abstract}

\section{ARTICLE HISTORY}

Received 15 January 2019

Revised 22 November 2019

Accepted 26 November 2019

\section{KEYWORDS}

African American; health disparities; obesity; physical activity; weight loss

\section{Introduction}

A disproportionate majority (57.2\%) of African American (Black) women are obese, compared to non-Hispanic White (White) women (38.2\%) (Flegal et al. 2016). Obesity increases individual risk of developing diseases, such as type 2 diabetes, hypertension, cardiovascular disease, and some cancers (American Diabetes Association 2007; Calle and Kaaks 2004; Calle et al. 2003; Schmitz et al. 2000). Behavioral weight loss interventions (BWI) can reduce weight-related disease risk through clinically significant weight loss of 5-10\% (American Diabetes Association 2007; Hamman et al. 2006; Jakicic et al. 2012; Krishnan et al. 2007; The Diabetes Prevention Program Research Group 2002; Wadden 
and Bray 2018; Wadden et al. 2009). Unfortunately, BWI are typically less effective for Black women, who often lose small amounts of weight $(2-3 \%)$ that are significantly less (2-3 kg less) than White women (Blackman Carr et al. 2018; Davis et al. 2015; Fitzgibbon et al. 2012; Goode et al. 2017; Samuel-Hodge et al. 2014; West et al. 2008; Wingo, Carson, and Ard 2014). While small reductions in weight are beneficial (Hamman et al. 2006; Knowler et al. 2003; Svetkey et al. 2005), the weight loss disparity indicates a need for more effective BWI for Black women.

Several factors may influence the racial disparity in BWI outcomes. Differential adherence to dietary and physical activity (PA) recommendations in BWI between Black and White women may play a role in the weight loss disparity. A 16-week randomized trial of diet and exercise found that race predicted adherence to dietary recommendations, with Blacks being less adherent than Whites (Epstein and Roemmich 2001). However, Davis et al. found that Blacks and Whites enrolled in a BWI did not differ in self-reported calorie intake (Davis et al. 2015). Additionally, compared to Black women, White women have exhibited significantly higher change in objectively measured PA and cardiorespiratory fitness levels (Davis et al. 2015; Walsh et al. 2004). Self-reported PA has been reported as higher in White vs. Black women, and PA adherence was strongly related to weight loss in a multicenter trial (Wadden et al. 2009). Taken together, this suggests that greater engagement in PA may improve weight loss.

Physical activity can account for as much as $20-25 \%$ of weight loss in BWI when combined with a calorie-restricted diet (Goodpaster et al. 2010; Jakicic and Davis 2011). High amounts of at least moderate-intensity PA (250-300 min/week) have been recommended for short- and long-term weight loss (Goodpaster et al. 2010; Jakicic and Davis 2011; Jakicic et al. 2014; Jeffery et al. 2003; U.S. Department of Health and Human Services 2018). Evidence from PA interventions that have included Black women identified the following elements as important to increase PA: supervised PA, prescribed PA goals, group exercise, social support, problem-solving, self-monitoring, modeling, feedback, and relevant barriers and enablers of PA (Artinian et al. 2010; Banks-Wallace and Conn 2002; Stuart-Shor et al. 2012; Whitt-Glover et al. 2009; Whitt-Glover and Kumanyika 2009).

Weight loss in Blacks may also be affected by cultural influences on the outcomes and targeted behaviors (Kumanyika, Whitt-Glover, and Haire-Joshu 2014). A reframed approach that incorporates the socio-cultural norms and perspectives of Blacks has been recommended (Kumanyika et al. 2007). Furthermore, given the role of PA in weight loss, increasing Black women's PA during BWI by applying a sociocultural, race- and genderbased lens to PA adoption, may improve weight loss. Thus, we conducted a trial in which we hypothesized that Black women randomized to a culturally relevant, PA-enhanced BWI (enhanced) would have greater weight loss and objectively-measured moderate-tovigorous PA (MVPA) than those in a standard BWI (standard) at 6-months post-baseline.

\section{Materials and methods}

\section{Participants}

Eligible women self-identified as Black, had a body mass index of $25-45 \mathrm{~kg} / \mathrm{m}^{2}$, and were 21-65 years old. Participants were required to be have low activity ( $\leq 75 \mathrm{~min} /$ week of selfreported MVPA) and willing to participate in face-to-face sessions. To self-monitor and 
receive feedback, reliable Internet access with a regularly used e-mail address was required. Exclusion criteria included weight loss (5-10\%) in the last 6 months, concurrent participation in another weight-related program, and taking weight loss medication. The Physical Activity Readiness Questionnaire evaluated physical limitations to PA (Physiology, 2002). Physician consent was required if an affirmative response was given to any item. Being or planning to become pregnant, use of insulin to manage type 2 diabetes, history of disordered eating, diagnosis of a major psychological disorder with change in medication dose in the past year, thyroid medication dose change in the last year, current or recent (last 5 years) cancer treatment, or relocation plans were also exclusion criteria.

\section{Recruitment}

We used passive and active recruitment strategies. Passive strategies included advertisement through university and local community listservs, flyers and Facebook ads. Active recruitment strategies included meeting with community leaders (e.g., church pastors) and participating in community events (e.g., health fairs) to distribute flyers and identify interested individuals. All recruitment methods directed individuals to a study website to complete an initial online screening form. Through the study website, 955 women made contact and completed the online screener. Those who were initially eligible through the online screener, were then contacted by study staff who completed a follow-up phone screening with 315 women (Figure 1 depicts the flow of individuals through the study). If women passed the phone screening, they were invited to an orientation session $(n=146)$ to learn more about the study. At orientation, study details were communicated, and a written informed consent document was signed by women who agreed to participate. Those interested in continuing participation scheduled their baseline assessment at that time. Once baseline assessments were completed, women $(\mathrm{n}=85)$ were randomized to one of two study groups. A total sample size of 66 was required to detect a $3.0 \mathrm{~kg}$ difference in change in weight between groups, with a power of $80 \%$ and two-sided alpha of 0.05 .

\section{Study design}

Computer-generated randomization to the standard or enhanced group occurred after baseline data were collected. A six-month post-baseline follow-up assessment was conducted to evaluate outcomes. Participants received $\$ 25$ for completing the assessment. The study was conducted in two cohorts from March 2016 to February 2017. The Institutional Review Board of the University of North Carolina at Chapel Hill approved the study.

\section{Intervention description: standard group}

The six-month standard intervention was adapted from published work modeled after the Diabetes Prevention Program and Look Ahead (American Diabetes Association 2007; Jakicic et al. 2012; The Diabetes Prevention Program Research Group 2002). Standard treatment included: 18 face-to-face group sessions, self-monitoring of daily weight, diet and activity with a mobile application (MyFitnessPal), and weekly e-mail feedback. 


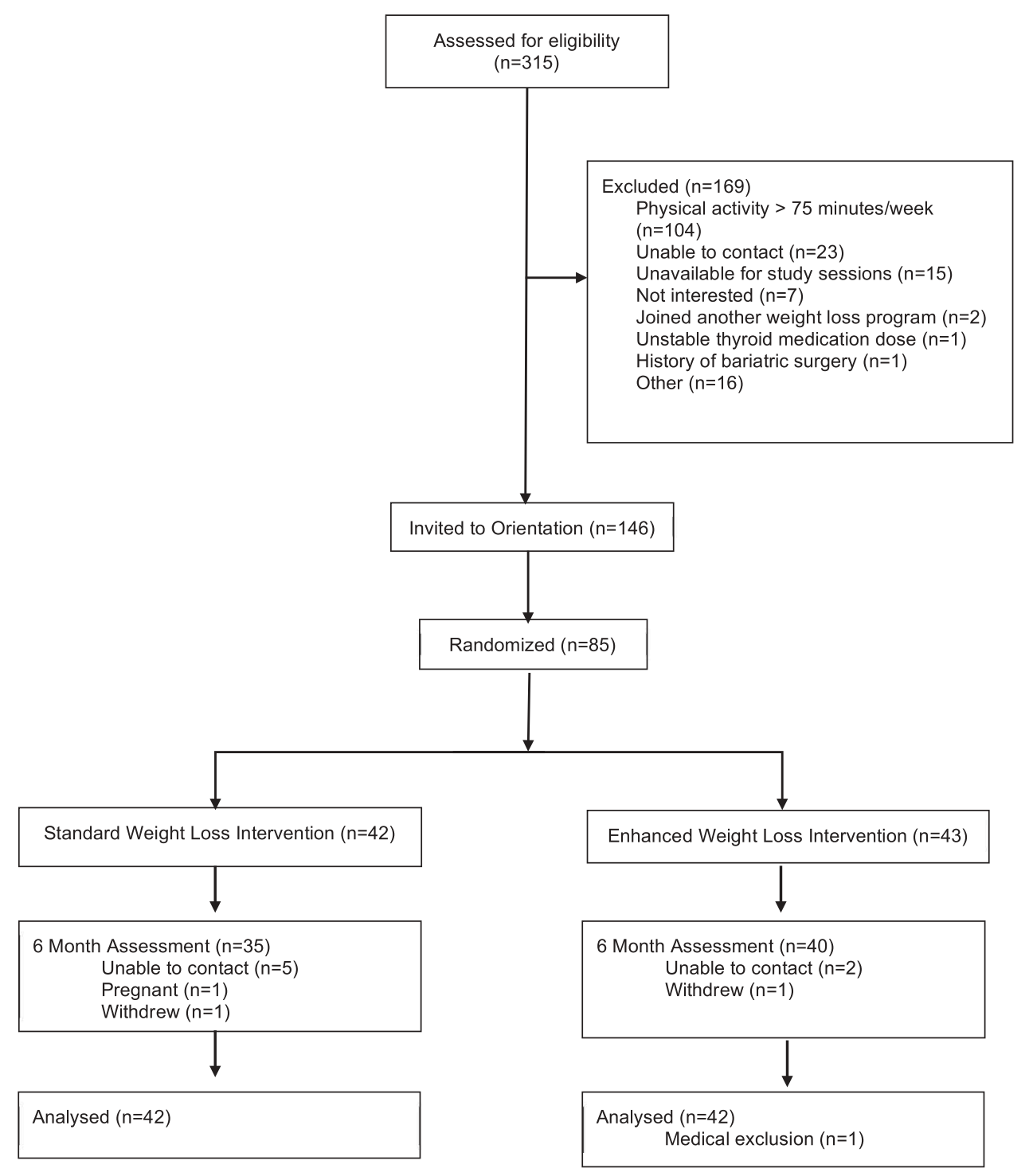

Figure 1. Study flow.

Participants received printed lessons at each group session. Photos within lessons were selected to match participants' race, representing a surface-level adaptation to lesson materials (Resnicow et al. 1999), but did not incorporate cultural values. Participants were prescribed daily calorie intake goals according to baseline weight $(1200 \mathrm{kcal} /$ day for $90 \mathrm{~kg}, 1500 \mathrm{kcal} /$ day for $>90 \mathrm{~kg}, 1800 \mathrm{kcal} /$ day for those $\geq 113 \mathrm{~kg}$ ) and received registered dietitian-created meal plan and sample menus. Weekly PA goals were prescribed to reach $300 \mathrm{~min} /$ week of MVPA progressively by 6 months. Progression toward the PA goal was based on self-reported MVPA (minutes/week) during recruitment. Weekly e-mail feedback, using self-monitoring records, provided behavioral guidance based on weekly weight change, average daily calorie intake and total minutes of PA. 


\section{Intervention description: enhanced group}

The enhanced group received the standard group treatment plus enhancements to support PA adherence. Reducing race- and gender-based PA barriers, not typically included in standard BWI, were targeted to improve participants' weight loss. Enhancements were also designed to incorporate cultural PA values and increase PA opportunities, which represented "deep structure" cultural adaptation that encompassed Black women's cultural values (Resnicow et al. 1999). The enhancements, including the cultural adaptation, were informed by qualitative and quantitative PA literature and shaped by an expanded obesity paradigm that promotes inclusion of the PA contexts and environments of Black women (Kumanyika et al. 2007). The barrier-reductionfocused enhancements included: barrier tip sheet, Facebook discussion, supervised group PA, weekly PA options, and Exercise Ambassadors (additional detail about each enhancement is detailed in Table 1).

Both the standard and enhanced interventions were delivered by the same interventionist, who was a Black woman (LBC).

\section{Measures}

All measures, except demographics, were collected at baseline and 6 months.

\section{Demographics}

Descriptive information was collected at baseline, including age, annual household income, and marital status.

\section{Anthropometrics}

Trained assessors collected anthropometric data. Assessors were not masked to participants' study group assignment. Height was measured with a wall-mounted stadiometer to the nearest $0.1 \mathrm{~cm}$ in duplicate. Weight was assessed in duplicate to the nearest $0.1 \mathrm{~kg}$ with a digital scale and participants in light clothing without shoes. After a five-minute rest period, three blood pressure readings were captured by an automated device. Waist circumference was measured in duplicate to the nearest $1.0 \mathrm{~cm}$.

\section{Dietary intake}

The Block Food Frequency Questionnaires for fat and fruit/vegetable intake assessed fruit/ vegetable servings (daily), total fat (g), and percent of calories from fat (Block et al. 1986).

\section{Physical activity}

The Paffenbarger Exercise Habits Questionnaire captured self-reported energy expenditure (kcal/week) (Paffenbarger et al. 1978). The SenseWear Armband Mini accelerometer (BodyMedia, Pittsburgh, PA), validated in previous studies, objectively measured MVPA (minutes/week) (Jeffery et al. 2003; Johannsen et al. 2010; St-Onge et al. 2007; Unick et al. 2017, 1-11). MVPA was defined as $\geq 3$ metabolic equivalents per minute. Participants were instructed to wear the armband for 7 days during all waking hours. Adherent wear was defined as at least 4 days for at least $10 \mathrm{~h}$ /day. 
Table 1. Enhanced group physical activity enhancements.

\begin{tabular}{|c|c|c|}
\hline Enhancement & Description & Targeted Barrier or Facilitator \\
\hline Barrier Tip Sheet & $\begin{array}{l}\text { Participant worksheet included with every lesson that } \\
\text { presented one physical activity barrier or facilitator } \\
\text { identified in the literature. } \\
\text { Participants employed problem-solving or goal-setting } \\
\text { techniques to address barrier or facilitator in small teams. } \\
\text { Tip sheet language incorporated sociocultural perspectives } \\
\text { and experiences of black women. }\end{array}$ & $\begin{array}{l}\text { Sample Barriers } \\
\text { - Hair care \& maintenance } \\
\text { - Superwoman schema } \\
\text { - Feared loss of desired curvy body } \\
\text { (femininity) becoming too } \\
\text { muscular (masculine) } \\
\text { - Time } \\
\text { - Sample Facilitators } \\
\text { - Collectivism } \\
\text { - Role modeling physical activity for } \\
\text { community }\end{array}$ \\
\hline Facebook Group & $\begin{array}{l}\text { A private Facebook group moderated by the interventionist } \\
\text { where topics coordinated with the barrier tip sheet. } \\
\text { Two to three moderator posts were made to facilitate } \\
\text { continued dialogue around the physical activity barrier or } \\
\text { facilitator. (see Fig. Y) }\end{array}$ & $\begin{array}{l}\text { Topics mirrored barrier tip sheet } \\
\text { examples. }\end{array}$ \\
\hline $\begin{array}{l}\text { Supervised } \\
\text { Group } \\
\text { Physical } \\
\text { Activity }\end{array}$ & $\begin{array}{l}\text { During lessons, a black female certified group fitness } \\
\text { instructor led } 30 \text { minutes of aerobic activity. Instruction } \\
\text { included demonstration of proper exercise technique, } \\
\text { assessment of exercise intensity (moderate or vigorous), and } \\
\text { emphasized exercise bouts of at least } 10 \text { continuous } \\
\text { minutes. }\end{array}$ & $\begin{array}{l}\text { Inexperience with exercise and physical } \\
\text { activity }\end{array}$ \\
\hline $\begin{array}{l}\text { Exercise } \\
\text { Ambassador }\end{array}$ & $\begin{array}{l}\text { Six ambassadors were recruited to serve as monthly role } \\
\text { models during supervised group physical activity, and to } \\
\text { discuss how they applied problem-solved or goal-set the } \\
\text { barrier or facilitator presented on the tip sheet during their } \\
\text { in-person visit and one week after in the interventionist- } \\
\text { moderated Facebook discussion. } \\
\text { Ambassadors were black women who maintained } \geq 5 \% \\
\text { weight loss for } \geq 6 \text { months, and maintained } \geq 150 \text { minutes of } \\
\text { moderate-to-vigorous PA for }>3 \text { months. }\end{array}$ & Lack of physical activity role models \\
\hline $\begin{array}{l}\text { Weekly Physical } \\
\text { Activity } \\
\text { Options }\end{array}$ & $\begin{array}{l}\text { Between sessions, participants were given } 4 \text { consistent } \\
\text { options to engage in PA. } \\
\text { (1) } 30 \mathrm{~min} \text { of exercise with fellow participant(s) } \\
\text { (2) } 30 \mathrm{~min} \text { of home instructional exercise video } \\
\text { (3) } 30 \mathrm{~min} \text { of exercise in a group fitness class } \\
\text { (4) } 30 \mathrm{~min} \text { their choice of exercise }\end{array}$ & - \\
\hline
\end{tabular}

\section{Process measures}

Study engagement was assessed with session attendance checklists and tracking of the number of weeks of self-monitoring. Adherent self-monitoring was defined as $\geq 3$ days, with $\geq 1000 \mathrm{kcal}$ intake/day. Total Facebook likes and comments per individual were captured in the enhanced group.

\section{Statistical analysis}

Differences in baseline characteristics were assessed with t-tests and chi-square tests. No baseline group differences were observed; therefore, analyses were unadjusted. A multiple linear model was used to compare groups using an intent-to-treat approach. Assumptions of the multiple linear model were tested to determine model fit, including visual assessment of the plots of residuals, which were adequate. Change in weight was the primary outcome, and change in objective MVPA was the secondary 
outcome. Total MVPA was not compared between groups. Baseline weight $(\mathrm{kg})$ and MVPA were included as control variables where appropriate. Any outcome variables that violated the assumption of normality were transformed to approximate a normal distribution of residuals. Self-reported PA and total weeks of self-monitoring were log transformed. Waist circumference underwent a square root transformation. We report the original variable means for ease of interpretation. Post hoc exploratory analyses were conducted to examine study adherence (attendance), engagement (selfmonitoring, Facebook participation) and the study outcomes (change in weight, MVPA). A $p$-value of $<0.05$ was considered statistically significant. One observation was excluded from analysis due to medical reasons. Analyses were conducted using SAS version 9.3 (SAS Institute).

\section{Results}

We screened 315 individuals for eligibility. The primary reason for ineligibility was selfreported PA $>75 \mathrm{~min} /$ week. Of the 315 women screened, 146 women were eligible and were invited to an orientation session (Figure 1). On average, participants were 48.30 (11.02) years old, weighed $97.90(14.22) \mathrm{kg}$, with a body mass index of $36.46(4.50) \mathrm{kg} / \mathrm{m}^{2}$ (Table 2). Over half of participants were married or living with a partner $(56.96 \%)$. No baseline between-group differences were seen in self-reported MVPA (kcal/week), daily fruit/vegetable servings, total grams or percent calories from fat.

\section{Retention}

Following orientation, when informed consent was gathered, completion of the baseline assessment was required for participation. After women completed the baseline assessment $(n=85)$, they were subsequently randomized to the standard $(n=42)$ or enhanced group $(n=43)$. No method was used to select participants from the pool of women invited to orientation. Rates of retention, defined as completion of the 6-month assessment, was not different between groups (standard vs. enhanced: $80.1 \%$ and $92.9 \% ; p=.31$ ).

\section{Change in weight}

Weight loss was not significantly different between the groups at 6-months post-baseline (standard vs. enhanced group: $-2.83 \mathrm{~kg}(-2.95 \%)$ vs. $-2.08 \mathrm{~kg}(-2.19 \%), p=.43)$. However, for

Table 2. Baseline demographic characteristics of participants by treatment arm.

\begin{tabular}{lcccc}
\hline & $\begin{array}{c}\text { Total } \\
(\mathrm{n}=85)\end{array}$ & $\begin{array}{c}\text { Standard } \\
(\mathrm{n}=42)\end{array}$ & $\begin{array}{c}\text { Enhanced } \\
(\mathrm{n}=43)\end{array}$ & $p$-Value \\
\hline Age (years), mean (sd) & $48.30(11.02)$ & $48.12(10.61)$ & $48.48(11.53)$ & .89 \\
Annual Household Income $\mathrm{n}(\%)$ & $34(39.44)$ & $14(32.43)$ & $20(47.06)$ & .21 \\
$\bullet<\$ 50,000 /$ year & $51(60.56)$ & $28(67.57)$ & $23(52.94)$ & \\
$\bullet \geq \$ 50,000 /$ year & & & & \\
Marital status $\mathrm{n}(\%)$ & $48(56.96)$ & $24(56.41)$ & $25(57.50)$ & .92 \\
$\bullet$ Married or living as married & $37(43.04)$ & $18(43.59)$ & $18(42.50)$ & \\
$\bullet$ Not married & & & & .23 \\
Weight $(\mathrm{kg})$ & $97.90(14.22)$ & $95.99(11.36)$ & $99.81(16.53)$ & .52 \\
BMI $\left(\mathrm{kg} / \mathrm{m}^{2}\right)$ & $36.46(4.50)$ & $36.12(4.40)$ & $36.78(4.62)$ & \\
\hline
\end{tabular}


all participants, Pearson correlation showed that change in weight over 6 months was inversely associated with the total number of sessions attended $(r=-0.39, p=.0006)$ and the total number of weeks participants self-monitored $(r=-0.35, p=.0032)$.

Groups differed significantly in the number of participants who achieved at least $5 \%$ weight loss. More women in the standard compared to the enhanced group lost at least 5\% of baseline weight $(17(39.5 \%)$ vs. $9(20.4 \%), p=.02)$. Overall, participants who lost at least $5 \%$ of baseline weight, compared to those who did not, were not significantly different in age, income or marital status, but did self-monitor for more weeks $(\beta(\mathrm{SE})=-4.43(1.70)$, $p=.01)$.

\section{Physical activity and diet}

Over 6 months, women in the standard group increased average minutes/week of objectively-measured MVPA by 43.93 (116.10), whereas women in the enhanced group increased by 15.29 (132.90) minutes/week (Table 3). Six-month change in objectivelymeasured $(p=.45)$ and self-reported $(p=.25)$ MVPA did not differ between groups, nor did the change in daily fruit/vegetable servings $(p=.47)$, total fat $(p=.34)$, or total percent fat $(p=.34 ;$ Table 4$)$.

\section{Anthropometric and cardiovascular outcomes}

By 6 months, all participants reduced their waist circumference and diastolic blood pressure. No between group difference appeared in change in waist circumference $(p=.89)$, change in systolic $(p=.18)$ or diastolic blood pressure at 6 months $(p=.21$; Table 3).

\section{Adherence}

Standard and enhanced group participants did not differ significantly in session attendance $(p=.41)$. Both groups attended approximately $50 \%$ of the 18 group sessions (standard vs. enhanced: mean $(S D)=10.85$ (5.86) vs. 9.83 (5.37)). Post hoc attendance was negatively correlated with weight $(r=-0.39, p=<0.001)$ and positively correlated with objectively-measured MVPA $(r=0.30, p=.02)$. Also, the mean number of weeks participants used the self-monitoring application did not differ between groups (standard vs enhanced group: 6.27 (7.10) vs. $4.31(5.56), p=.20)$. Enhanced group participants' Facebook engagement (total likes $(r=-0.19, p=.26)$ and comments $(r=0.01, p=.94)$ ) was not correlated with weight loss.

\section{Discussion}

This randomized trial compared the effects of a culturally-relevant, PA-enhanced BWI versus a standard BWI among Black women. Average weight loss was not different between groups at 6 months. However, a greater proportion of participants in the standard group achieved a 5\% weight loss compared to enhanced group. Though the enhanced group treatment sought to increase MVPA, change in mean objective MVPA did not differ between groups. Dietary and adherence measures also did not differ by 
Table 3. Objective and self-reported physical activity at 6 months.

\begin{tabular}{|c|c|c|c|c|}
\hline \multirow[b]{2}{*}{ Outcome } & \multicolumn{2}{|c|}{ Means (SD) } & \multicolumn{2}{|l|}{ Regression Results } \\
\hline & Standard & Enhanced & Parameter Estimate(SE) & $p$-Value \\
\hline \multicolumn{5}{|l|}{ Baseline Physical Activity } \\
\hline Total MVPA, objective (minutes/week) & $57.83(79.00)$ & $76.37(117.00)$ & - & - \\
\hline $\begin{array}{l}\text { Total physical activity, } \\
\text { self-reported (kcal/week) }\end{array}$ & $312.50(476.30)$ & $333.50(461.70)$ & - & - \\
\hline \multicolumn{5}{|l|}{ 6-Month Physical Activity } \\
\hline Total MVPA, objective (minutes/week) & $102.00(96.87)$ & $88.59(161.50)$ & - & - \\
\hline Change in MVPA, objective (minutes/week) & $43.93(116.10)$ & $15.29(132.90)$ & $23.08(30.44)$ & .45 \\
\hline $\begin{array}{l}\text { Total physical activity, } \\
\text { self-reported (kcal/week) }\end{array}$ & $705.50(761.30)$ & $721.20(925.6)$ & - & - \\
\hline $\begin{array}{l}\text { Change in physical activity, } \\
\text { self-reported (kcal/week) }\end{array}$ & $409.00(918.40)$ & $391.40(947.20)$ & $0.40(0.35)$ & .25 \\
\hline
\end{tabular}

Table 4. Means of change in weight, dietary intake, waist circumference, blood pressure, and total adherence at 6 months by group.

\begin{tabular}{|c|c|c|c|c|c|c|c|}
\hline \multirow[b]{3}{*}{ Outcome } & \multirow{2}{*}{\multicolumn{3}{|c|}{$\frac{\text { Baseline }}{\text { Means (SD) }}$}} & \multicolumn{4}{|c|}{ Change at 6 Months } \\
\hline & & & & \multicolumn{2}{|c|}{ Means (SD) } & \multicolumn{2}{|c|}{ Regression Results } \\
\hline & Standard & Enhanced & $p$-Value & Standard & Enhanced & $\begin{array}{c}\text { Parameter } \\
\text { Estimate(SE) }\end{array}$ & $p$-Value \\
\hline Weight(kg) & $95.99(11.36)$ & 99.81 (16.53) & .23 & $-2.83(3.82)$ & $-2.08(3.91)$ & $-0.73(0.92)$ & .43 \\
\hline Total fat(g/day) & $101.20(30.98)$ & $96.30(21.54)$ & .42 & $-7.20(14.24)$ & $-10.80(15.77)$ & $3.41(3.54)$ & .34 \\
\hline Calories from fat (\%) & $36.41(7.74)$ & $35.20(5.38)$ & .42 & $-1.80(3.56)$ & $-2.70(3.94)$ & $0.85(0.88)$ & .34 \\
\hline $\begin{array}{l}\text { Fruit/vegetable intake } \\
\text { (servings/day) }\end{array}$ & $2.82(1.23)$ & $2.81(1.04)$ & .94 & $0.47(1.52)$ & $0.36(0.88)$ & $0.18(0.25)$ & .47 \\
\hline Session attendance & - & - & - & $10.85(5.86)$ & $9.83(5.37)$ & 1.27 & .31 \\
\hline $\begin{array}{l}\text { Total weeks self- } \\
\text { monitored }\end{array}$ & - & - & - & $6.27(7.10)$ & $4.31(5.66)$ & $0.27(0.27)$ & .32 \\
\hline $\begin{array}{l}\text { Waist Circumference } \\
\text { (in.) }\end{array}$ & $82.08(20.03)$ & 81.39 (17.75) & .87 & $-2.36(7.85)$ & $-1.20(8.62)$ & $-0.15(0.78)$ & .89 \\
\hline $\begin{array}{l}\text { Change in systolic } \\
\text { blood pressure } \\
(\mathrm{mmHg})\end{array}$ & $121.70(18.26)$ & $127.30(17.34)$ & .16 & $0.48(11.03)$ & $-3.65(11.20)$ & $3.37(2.48)$ & .18 \\
\hline $\begin{array}{l}\text { Change in diastolic } \\
\text { blood pressure } \\
\text { (mmHg) }\end{array}$ & 78.67 (12.76) & 77.55 (11.16) & .68 & $-3.23(11.76)$ & $-5.15(11.15)$ & $3.06(2.41)$ & .21 \\
\hline
\end{tabular}

group. Overall, participants attended approximately half of the offered group sessions and self-monitored for approximately $25 \%$ of the study period. These findings indicate that the enhanced group treatment did not produce outcomes different from the standard group treatment.

All participants experienced small weight losses $(\sim 2 \%)$, which is typical for Black women in BWI (Fitzgibbon et al. 2008; Goode et al. 2017; Svetkey et al. 2005). While small amounts of weight loss are beneficial, the BWI target remains 5-10\% weight reduction to achieve health benefits (Hamman et al. 2006). Small weight losses may also reflect subpar attendance across study groups. Though attendance at all sessions was recommended, the average of 50\% attendance was not unexpected. The observed inverse correlation between weight and attendance was expected and consistent with previous trials (Davis et al. 2015; Fitzgibbon et al. 2008). Notably, proportionally more women in the standard compared to the enhanced group lost at least $5 \%$ of baseline weight. Standard 
predictors of at least $5 \%$ weight loss, such as age and adherence, were not predictive in this study (Tate et al. 2017). This was unexpected. Perhaps a more equitable focus on dietary and PA behavior change was communicated in the standard group compared to enhanced group.

Participants' objective MVPA was far below the six-month goal (300 min/week). Change in objective and self-reported MVPA was not different between groups and was small in comparison to other studies with predominantly White samples (Davis et al. 2015; Jeffery et al. 2003). However, the average objectively-measured MVPA below 150 min/week, has been previously observed among Blacks in a BWI (Davis et al. 2015). Studies that produced higher PA at 6 months maintained weekly session frequency (Davis et al. 2015; Jeffery et al. 2003). In this study, group session frequency decreased from weekly to biweekly after 3 months. Perhaps the intervention dose delivered was insufficient to support such great PA change in the initially low-active participants.

The lower than expected PA engagement in the enhanced vs. standard group may also have reflected a greater focus on addressing intra- and interpersonal PA barriers. However, institutional, community, and policy level barriers that likely affect PA behavior needed to be addressed to improve enhanced group responsiveness (Golden and Earp 2012; Kumanyika et al. 2007; Kumanyika, Whitt-Glover, and Haire-Joshu 2014; McLeroy et al. 1988). Future studies may need to expand PA barrier reduction efforts to improve engagement.

Study engagement through session attendance was necessary to gain exposure to the majority of enhancements and small team support. Across study groups, participants attended about half of the group sessions, a rate that is not unusual, nor unexpected, for this population during weight control interventions (Davis et al. 2015; Fitzgibbon et al. 2008). While one might expect the racially homogenous composition of the study sample to foster greater engagement due to similarity, this was not observed in this study. Less than ideal attendance meant some teams were small and potentially less effective at addressing PA barriers, and women had decreased opportunities for group interaction to build cohesion (Harden et al. 2014). Consequently, the intended formation of culturally relevant interpersonal non-kin and sisterhood bonds may not have occurred. Participants' attendance rate also limited contact with the Exercise Ambassadors, who attended $100 \%$ of their monthly group session appearances. Thus, participants did not receive full exposure to Ambassadors who modeled successful PA adoption, barrier management and provided social support. Importantly, monthly Exercise Ambassador visits may have been inadequate to meet Black women's need for PA role models and increased PA exposure (Harley et al. 2009; Joseph et al. 2015; Young et al. 2002).

Furthermore, the sub-optimal attendance rate-limited participation in supervised PA during enhanced group sessions. While the supervised PA was likely insufficient, the small change in objective MVPA likely reflects low adoption outside of group sessions. Taken together, improved attendance is needed, as is the provision of sufficient structured PA opportunities, a strategy that has produced significant PA change (Whitt-Glover et al. 2014). This approach may answer hypotheses about whether greater PA engagement among Black women enhances weight loss.

The enhanced group Facebook component aimed to engage participants in PA and barrier reduction further. While modest Facebook engagement has been observed previously in this population, we observed low engagement (Joseph et al. 2015). Importantly, 
Facebook likes were directly correlated with objectively-measured MVPA but not weight loss. Greater Facebook engagement may have produced better PA outcomes through continued interaction with PA and barrier reduction content. Online social networking tools have been recommended for use in Internet-delivered PA interventions with Black women to provide social connections (Durant et al. 2014). Furthermore, Facebook engagement has been associated with weight loss in other studies (Hales, Davidson, and Turner-McGrievy 2014). Including a Facebook, component may still be a practical tool to increase PA and ultimately weight loss, but improved engagement strategies are necessary.

In addition to PA increase, reduced calorie intake is essential for weight loss. Both groups lowered their self-reported intake, a change likely responsible for the small weight losses observed (Fitzgibbon et al. 2008). While both groups made positive changes to dietary intake, no between group differences emerged. The limited weight loss observed likely also reflects low self-monitoring (a few weeks, on average), a finding observed among Blacks in another intervention (Davis et al. 2015). Self-monitoring adherence was associated with greater weight loss in this and other BWI (Krukowski et al. 2013). While we did not expect dietary and self-monitoring group differences to emerge, it helps explain the lower weight loss.

Our study produced small weight losses typically seen among Black women in standard BWI. Therefore, ample opportunity exists to improve both PA and weight loss for this population. Physical activity barrier reduction techniques should be investigated further, with an expanded scope to target the broader context of PA barriers.

\section{Strengths and limitations}

A major strength of this study was the randomized controlled trial design to compare intervention effectiveness. By doing so, we were able to contribute to the field's understanding of what may be a more effective BWI for Black women. The unexpected null results partially fill the evidence gap concerning Black women in BWI, by indicating the intervention approaches used were not more effective for weight loss than standard BWI. The computed effect size of $3 \mathrm{~kg}$ may have been overly optimistic, and sample size may have not have provided adequate statistical power to detect a smaller perhaps more reasonably expected between-group change in weight. Null results are valuable, informing areas where future study is and is not required. Another strength was objective MVPA measurement, which enabled a clear evaluation of the outcome. Our study was further strengthened by the incorporation of the expanded obesity paradigm that promotes inclusion of the context of weight-related behaviors in Blacks (Kumanyika et al. 2007). The PA enhancements addressed this context by including PA barriers specific to Black women that are usually not included in BWI (Resnicow et al. 1999).

While incorporating these PA barriers was a strength, a limitation persists in the need for systematic conceptualization, operationalization, reporting and assessment of cultural adaptations to interventions (Kong et al. 2014; Kumanyika, Whitt-Glover, and Haire-Joshu 2014). Additionally, the PA barriers included mostly addressed intra- and interpersonal contexts, but not community or policy contexts. Inadvertently, this may have excluded important barriers that affect PA engagement. The strategy of PA barrier reduction has been explored previously and remains relevant to address barriers that deter PA adoption and maintenance (Hall et al. 2013; Pekmezi et al. 2016, 2013; Ray 2014). Furthermore, bringing together Black 
women to a weight loss group led by a Black woman may have resulted in more cultural relevance in the standard group than we expected. However, interventionist-participant race concordance may not have affected weight loss, as demonstrated in a previous weight control trial (Batch et al. 2013). Importantly, the enhanced treatment in our study did not increase PA to the goal amount; so, despite research indicating the role of PA in maximizing weight loss (Goodpaster et al. 2010; Jakicic and Davis 2011), questions remain about ways to increase PA to higher levels in Black women. Finally, BMI is an imperfect measure, but it represents one part of the standard approach to screening and recruitment. For this study focused on Black women, we extended the traditional range of BMI eligibility from 25 to 40 to $25-45$ to acknowledge the frequent finding that Black women often enter weight control interventions at a higher weight than their White female counterparts. Though imperfect, BMI remains the practical measure for assessing weight status for weight control interventions that may have broadly-applicable outcomes.

Results of this study indicate multiple areas for continued investigation. Future interventions should incorporate barrier reduction strategies. Formative work may be a necessary step to elucidate relevant barriers and develop appropriate strategies. Importantly, barriers may extend beyond the individual level to include community and policy levels, all of which can influence PA engagement. Interdisciplinary design of BWI are likely necessary to address barriers above the individual socioecological level. Relatedly, many of the PA enhancements were delivered during group sessions, where attendance was less than optimal. Different attendance strategies and BWI delivery modes, other than face-to-face, likely need to be explored. Importantly, adoption of PA was low, limiting examination of the central question, whether higher PA would yield greater weight loss in Black women. Finally, while the present study was sufficiently powered to detect a $3 \mathrm{~kg}$ between-group difference in weight loss, a larger sample size is required to adequately power future studies in which smaller differences may be expected and could thus be detected. Future interventions may seek to improve Black women's self-monitoring adherence and program attendance. Improving both may bolster dietary and PA change to achieve clinically significant weight loss. In sum, more investigation is warranted, especially given the persistent need for culturally informed and responsive intervention approaches to improve weight loss and behavioral outcomes in this population (Goode et al. 2017; Kumanyika et al. 2007; Whitt-Glover et al. 2014).

\section{Conclusions}

Neither weight loss nor change in objectively-measured MVPA after 6 months differed between participants randomized to the standard or enhanced behavioral weight loss intervention. Findings suggest that the enhanced BWI was not more effective than standard BWI. Improved self-monitoring adherence and attendance may offer pathways to bolster Black women' weight loss in BWI. The dual disparity of disproportionately high obesity prevalence and sub-optimal weight loss in BWI among Black women persists. Thus, further study and novel approaches to design and implement more effective BWI that consistently yield clinically meaningful weight loss among Black women is imperative. 


\section{References}

American Diabetes Association. 2007. Reduction in weight and cardiovascular disease risk factors in individuals with type 2 diabetes: One-year results of the look AHEAD trial. Diabetes Care 30 (6):1374-83. doi:10.2337/dc07-0048.

Artinian, N. T., G. F. Fletcher, D. Mozaffarian, P. Kris-Etherton, L. Van Horn, A. H. Lichtenstein, and N. S. Redeker. 2010. Interventions to promote physical activity and dietary lifestyle changes for cardiovascular risk factor reduction in adults. A scientific statement from the American Heart Association. Circulation 122:406-41. doi:10.1161/CIR.0b013e3181e8edf1.

Banks-Wallace, J., and V. Conn. 2002. Interventions to promote physical activity among African American women. Public Health Nursing 19 (5):321-35. doi:10.1046/j.1525-1446.2002.19502.x.

Batch, B. C., J. D. Ard, W. M. Vollmer, K. Funk, L. J. Appel, V. J. Stevens, ... L. P. Svetkey. 2013. Impact of participant and interventionist race concordance on weight loss outcomes. Obesity 21 (4):712-17. doi:10.1002/oby.20270.

Blackman Carr, L., C. Samuel-Hodge, D. S. Ward, K. R. Evenson, S. I. Bangdiwala, and D. F. Tate. 2018. Racial differences in weight loss mediated by engagement and behavior change. Ethnicity \& Disease 28 (1):43-48. doi:10.18865/ed.28.1.43.

Block, G., A. M. Hartman, C. M. Dresser, M. D. Carroll, J. Gannon, and L. Gardner. 1986. A data-based approach to diet questionnaire design and testing. American Journal of Epidemiology 124 (3):453-69. doi:10.1093/oxfordjournals.aje.a114416.

Calle, E. E., and R. Kaaks. 2004. Overweight, obesity and cancer: Epidemiological evidence and proposed mechanisms. Nature Reviews Cancer 4 (8):579. doi:10.1038/nrc1408.

Calle, E. E., C. Rodriguez, K. Walker-Thurmond, and M. J. Thun. 2003. Overweight, obesity, and mortality from cancer in a prospectively studied cohort of US adults. New England Journal of Medicine 348 (17):1625-38. doi:10.1056/NEJMoa021423.

Davis, K. K., D. F. Tate, W. Lang, R. H. Neiberg, K. Polzien, A. D. Rickman, K. Erickson, and J. M. Jakicic. 2015. Racial differences in weight loss among adults in a behavioral weight loss intervention: Role of diet and physical activity. Journal of Physical Activity and Health 12 (12):1558-66. doi:10.1123/jpah.2014-0243.

The Diabetes Prevention Program Research Group. 2002. The Diabetes Prevention Program (DPP): Description of lifestyle intervention. Diabetes Care 25 (12):2165-71. doi:10.2337/ diacare.25.12.2165.

Durant, N. H., R. P. Joseph, A. Cherrington, Y. Cuffee, B. Knight, D. Lewis Jr., and J. J. Allison. 2014. Peer reviewed: Recommendations for a culturally relevant Internet-based tool to promote physical activity among overweight young African American women, Alabama, 2010-2011. Preventing Chronic Disease 11. doi:10.5888/pcd11.130169.

Epstein, L. H., and J. N. Roemmich. 2001. Reducing sedentary behavior: Role in modifying physical activity. Exercise and Sport Sciences Reviews 29 (3):103-08. doi:10.1097/00003677-20010700000003 .

Fitzgibbon, M. L., M. Stolley, L. Schiffer, L. Sharp, V. Singh, L. Van Horn, and A. Dyer. 2008. Obesity reduction black intervention trial (ORBIT): Design and baseline characteristics. Journal of Women's Health 17 (7):1099-110. doi:10.1089/jwh.2007.0614.

Fitzgibbon, M. L., L. M. Tussing-Humphreys, J. S. Porter, I. K. Martin, A. Odoms-Young, and L. K. Sharp. 2012. Weight loss and African-American women: A systematic review of the behavioural weight loss intervention literature. Obesity Reviews 13 (3):193-213. doi:10.1111/ j.1467-789X.2011.00945.x.

Flegal, K. M., D. Kruszon-Moran, M. D. Carroll, C. D. Fryar, and C. L. Ogden. 2016. Trends in obesity among adults in the United States, 2005 to 2014. JAMA 315 (21):2284-91. doi:10.1001/ jama.2016.6458.

Golden, S. D., and J. A. L. Earp. 2012. Social ecological approaches to individuals and their contexts: Twenty years of health education \& behavior health promotion interventions. Health Education \& Behavior 39 (3):364-72. doi:10.1177/1090198111418634. 
Goode, R. W., M. A. Styn, D. D. Mendez, and T. L. Gary-Webb. 2017. African Americans in standard behavioral treatment for obesity, 2001-2015: What have we learned? Western Journal of Nursing Research 39 (8):1045-69. doi:10.1177/0193945917692115.

Goodpaster, B. H., J. P. DeLany, A. D. Otto, L. Kuller, J. Vockley, J. E. South-Paul, ... K. C. Hames. 2010. Effects of diet and physical activity interventions on weight loss and cardiometabolic risk factors in severely obese adults: A randomized trial. JAMA 304 (16):1795-802. doi:10.1001/ jama.2010.1505.

Hales, S. B., C. Davidson, and G. M. Turner-McGrievy. 2014. Varying social media post types differentially impacts engagement in a behavioral weight loss intervention. Translational Behavioral Medicine 4 (4):355-62. doi:10.1007/s13142-014-0274-z.

Hall, R. R., S. Francis, M. Whitt-Glover, K. Loftin-Bell, K. Swett, and A. J. McMichael. 2013. Hair care practices as a barrier to physical activity in African American women. JAMA Dermatology 149 (3):310-14. doi:10.1001/jamadermatol.2013.1946.

Hamman, R. F., R. R. Wing, S. L. Edelstein, J. M. Lachin, G. A. Bray, L. Delahanty, ... X. Pi-Sunyer. 2006. Effect of weight loss with lifestyle intervention on risk of diabetes. Diabetes Care 29 (9):2102-107. doi:10.2337/dc06-0560.

Harden, S. M., P. A. Estabrooks, S. K. Mama, and R. E. Lee. 2014. Longitudinal analysis of minority women's perceptions of cohesion: The role of cooperation, communication, and competition. International Journal of Behavioral Nutrition and Physical Activity 11 (1):57. doi:10.1186/14795868-11-57.

Harley, A. E., J. Buckworth, M. L. Katz, S. K. Willis, A. Odoms-Young, and C. A. Heaney. 2009. Developing long-term physical activity participation: A grounded theory study with African American women. Health Education \& Behavior 36 (1):97-112. doi:10.1177/1090198107306434.

Jakicic, J. M., and K. K. Davis. 2011. Obesity and physical activity. The Psychiatric Clinics of North America 34 (4):829-40. doi:10.1016/j.psc.2011.08.009.

Jakicic, J. M., D. F. Tate, W. Lang, K. K. Davis, K. Polzien, R. H. Neiberg, ... K. Erickson. 2014. Objective physical activity and weight loss in adults: The step-up randomized clinical trial. Obesity 22 (11):2284-92. doi:10.1002/oby.20830.

Jakicic, J. M., D. F. Tate, W. Lang, K. K. Davis, K. Polzien, A. D. Rickman, ... E. A. Finkelstein. 2012. Effect of a stepped-care intervention approach on weight loss in adults: A randomized clinical trial. JAMA 307 (24):2617-26. doi:10.1001/jama.2012.6866.

Jeffery, R. W., R. R. Wing, N. E. Sherwood, and D. F. Tate. 2003. Physical activity and weight loss: Does prescribing higher physical activity goals improve outcome? The American Journal of Clinical Nutrition 78 (4):684-89. doi:10.1093/ajcn/78.4.684.

Johannsen, D. L., M. A. Calabro, J. Stewart, W. Franke, J. C. Rood, and G. J. Welk. 2010. Accuracy of armband monitors for measuring daily energy expenditure in healthy adults. Medicine and Science in Sports and Exercise 42 (11):2134-40. doi:10.1249/MSS.0b013e3181e0b3ff.

Joseph, R. P., C. Keller, M. A. Adams, and B. E. Ainsworth. 2015. Print versus a culturally-relevant Facebook and text message delivered intervention to promote physical activity in African American women: A randomized pilot trial. BMC Women's Health 15 (1):30. doi:10.1186/ s12905-015-0186-1.

Knowler, W., E. Barrett-Connor, S. Fowler, R. Hamman, J. Lachin, E. Walker, and D. Nathan. 2003. Reduction in the incidence of type 2 diabetes with lifestyle intervention or metformin. Scandinavian Journal of Medicine \& Science in Sports 13 (3):208.

Kong, A., L. M. Tussing-Humphreys, A. M. Odoms-Young, M. R. Stolley, and M. L. Fitzgibbon. 2014. Systematic review of behavioural interventions with culturally adapted strategies to improve diet and weight outcomes in African American women. Obesity Reviews 15 (S4):62-92. doi:10.1111/obr.12203.

Krishnan, S., L. Rosenberg, L. Djoussé, L. A. Cupples, and J. R. Palmer. 2007. Overall and central obesity and risk of type 2 diabetes in US black women. Obesity 15 (7):1860-66. doi:10.1038/ oby.2007.220.

Krukowski, R. A., J. Harvey-Berino, Z. Bursac, T. Ashikaga, and D. S. West. 2013. Patterns of success: Online self-monitoring in a web-based behavioral weight control program. Health Psychology 32 (2):164. doi:10.1037/a0028135. 
Kumanyika, S., M. Whitt-Glover, and D. Haire-Joshu. 2014. What works for obesity prevention and treatment in black Americans? Research directions. Obesity Reviews 15 (S4):204-12. doi:10.1111/ obr.12213.

Kumanyika, S., M. C. Whitt-Glover, T. L. Gary, T. E. Prewitt, A. M. Odoms-Young, J. BanksWallace, ... K. J. Lancaster. 2007. Expanding the obesity research paradigm to reach African American communities. Preventing Chronic Disease 4 (4):1-22.

McLeroy, K. R., D. Bibeau, A. Steckler, and K. Glanz. 1988. An ecological perspective on health promotion programs. Health Education Quarterly 15 (4):351-77. doi:10.1177/ 109019818801500401.

Paffenbarger, J., S. Ralph, A. L. Wing, and R. T. Hyde. 1978. Physical activity as an index of heart attack risk in college alumni. American Journal of Epidemiology 108 (3):161-75. doi:10.1093/ oxfordjournals.aje.a112608.

Pekmezi, D., C. Ainsworth, R. Joseph, M. S. Bray, E. Kvale, S. Isaac, ... W. Demark-Wahnefried. 2016. Rationale, design, and baseline findings from HIPP: A randomized controlled trial testing a home-based, individually-tailored physical activity print intervention for African American women in the Deep South. Contemporary Clinical Trials 47:340-48. doi:10.1016/j. cct.2016.02.009.

Pekmezi, D., B. Marcus, K. Meneses, M. L. Baskin, J. D. Ard, M. Y. Martin, ... W. DemarkWahnefried. 2013. Developing an intervention to address physical activity barriers for AfricanAmerican women in the deep south (USA). Women's Health 9 (3):301-12. doi:10.2217/ whe.13.20.

Physiology, C. S. f. E. 2002. Physical activity readiness questionnaire PAR-Q (revised). Ottawa, Ontario: Canadian Society for Exercise Physiology.

Ray, R. 2014. An intersectional analysis to explaining a lack of physical activity among middle class black women. Sociology Compass 8 (6):780-91. doi:10.1111/soc4.12172.

Resnicow, K., T. Baranowski, J. S. Ahluwalia, and R. L. Braithwaite. 1999. Cultural sensitivity in public health: Defined and demystified. Ethnicity \& Disease 9 (1):10-21.

Samuel-Hodge, C., C. Johnson, D. Braxton, and M. Lackey. 2014. Effectiveness of diabetes prevention program translations among African Americans. Obesity Reviews 15 (S4):107-24. doi:10.1111/obr.12211.

Schmitz, K., D. Jacobs Jr., A. Leon, P. Schreiner, and B. Sternfeld. 2000. Physical activity and body weight: Associations over ten years in the CARDIA study. International Journal of Obesity 24 (11):1475. doi:10.1038/sj.ijo.0801415.

St-Onge, M., D. Mignault, D. B. Allison, and R. Rabasa-Lhoret. 2007. Evaluation of a portable device to measure daily energy expenditure in free-living adults-. The American Journal of Clinical Nutrition 85 (3):742-49. doi:10.1093/ajcn/85.3.742.

Stuart-Shor, E. M., K. A. Berra, M. W. Kamau, and S. K. Kumanyika. 2012. Behavioral strategies for cardiovascular risk reduction in diverse and underserved racial/ethnic groups. Circulation 125 (1):171-84. doi:10.1161/CIRCULATIONAHA.110.968495.

Svetkey, L., T. Erlinger, W. Vollmer, A. Feldstein, L. Cooper, L. Appel, ... V. Stevens. 2005. Effect of lifestyle modifications on blood pressure by race, sex, hypertension status, and age. Journal of Human Hypertension 19 (1):21. doi:10.1038/sj.jhh.1001770.

Tate, D. F., C. G. Valle, M. M. Crane, B. T. Nezami, C. D. Samuel-Hodge, K. E. Hatley, ... K. Polzien. 2017. Randomized trial comparing group size of periodic in-person sessions in a remotely delivered weight loss intervention. International Journal of Behavioral Nutrition and Physical Activity 14 (1):144. doi:10.1186/s12966-017-0599-3.

U.S. Department of Health and Human Services. 2018. Physical activity guidelines for Americans. Washington, DC: U.S. Department of Health and Human Services.

Unick, J. L., W. Lang, D. F. Tate, D. S. Bond, M. A. Espeland, and R. R. Wing. 2017. Objective estimates of physical activity and sedentary time among young adults. Journal of Obesity 2017:1-11. doi:10.1155/2017/9257564.

Wadden, T. A., and G. A. Bray. 2018. Handbook of obesity treatment. New York, USA: Guilford Publications. 
Wadden, T. A., D. S. West, R. H. Neiberg, R. R. Wing, D. H. Ryan, K. C. Johnson, ... M. Z. Vitolins. 2009. One-year weight losses in the Look AHEAD study: Factors associated with success. Obesity 17 (4):713-22. doi:10.1038/oby.2008.637.

Walsh, M. C., G. R. Hunter, B. Sirikul, and B. A. Gower. 2004. Comparison of self-reported with objectively assessed energy expenditure in black and white women before and after weight loss. The American Journal of Clinical Nutrition 79 (6):1013-19. doi:10.1093/ajcn/79.6.1013.

West, D. S., T. E. Prewitt, Z. Bursac, and H. C. Felix. 2008. Weight loss of black, white, and Hispanic men and women in the Diabetes Prevention Program. Obesity 16 (6):1413-20. doi:10.1038/ oby.2008.224.

Whitt-Glover, M., N. Keith, T. Ceaser, K. Virgil, L. Ledford, and R. Hasson. 2014. A systematic review of physical activity interventions among African American adults: Evidence from 2009 to 2013. Obesity Reviews 15 (S4):125-45. doi:10.1111/obr.12205.

Whitt-Glover, M. C., D. J. Brand, M. E. Turner, S. A. Ward, and E. M. Jackson. 2009. Increasing physical activity among African-American women and girls. Current Sports Medicine Reports 8 (6):318-24. doi:10.1249/JSR.0b013e3181c27ade.

Whitt-Glover, M. C., and S. K. Kumanyika. 2009. Systematic review of interventions to increase physical activity and physical fitness in African-Americans. American Journal of Health Promotion 23 (6_suppl):S33-S56. doi:10.4278/ajhp.070924101.

Wingo, B., T. Carson, and J. Ard. 2014. Differences in weight loss and health outcomes among African Americans and whites in multicentre trials. Obesity Reviews 15 (S4):46-61. doi:10.1111/ obr.2014.15.issue-s4.

Young, D. R., X. He, J. Harris, and I. Mabry. 2002. Environmental, policy, and cultural factors related to physical activity in well-educated urban African American women. Women \& Health 36 (2):29-41. doi:10.1300/J013v36n02_03. 